\title{
Management of craniofacial injuries: a primer for residents
}

\author{
Amit Agrawal ${ }^{1}$, Vijay Mishra ${ }^{2}$, Harsha Jain ${ }^{3}$, \\ Umamaheshwar Reddy V. ${ }^{4}$ \\ ${ }^{1}$ Professor of Neurosurgery, Department of Neurosurgery, Narayana Medical College Hospital, \\ Chinthareddypalem, Nellore, Andhra Pradesh (India) \\ ${ }^{2}$ Senior Lecturer, School of Dental Sciences, Sharda University, Greater NOIDA (UP) \\ ${ }^{3}$ Associate Professor, School of Dental Sciences, Sharda University, Greater NOIDA (UP) \\ ${ }^{4}$ Assistant Professor of Radiology, Department of Radiology, Narayana Medical College \\ Hospital, Chinthareddypalem, Nellore, Andhra Pradesh (India)
}

\begin{abstract}
Craniofacial injuries can occur in a significant proportion in traumatic brain injury patients and can be associated with many other concomitant life-threatening systemic injuries i.e. limbs fractures, chest injuries, spinal injuries and orbital injuries. An understanding of the presentations of craniofacial injuries, associated systemic injuries and patterns of traumatic brain injuries is crucial for improving care, survival and recovery of these patients. In present article we discuss the approach to craniofacial injuries which is based on time tested principles of surgery a good understanding of surgical anatomy, detailed history, accurate yet elaborative clinical evaluation, appropriate radiological investigations and decision to select management protocol for a given case. Evaluation of these patients should include a coordinated and systematic examination to aim to evaluate of all areas and all the residents
\end{abstract}

while examining these patients in emergency room should remember that facial swelling, altered sensorium, restless patient, presence of endotracheal and nasogastric tube can obscure the detail examination and distort the facial appearance.

Key words: craniofacial trauma, maxillofacial Injuries, traumatic brain injury, head injuries.

\section{Introduction}

Craniofacial trauma is one of the most challenging injuries that are posed by prehospital care providers and personnel's involved in emergency care. (1) These injuries can not only be life-threatening (as these can compromise airway or can cause significant hemorrhage) but also cause disfigurement. (2, 3) In present article we discuss the approach to craniofacial injuries which is based on time tested principles of surgery a good understanding of surgical anatomy, detailed 
history, accurate yet elaborative clinical evaluation, appropriate radiological investigations and decision to select management protocol for a given case.

\section{Etiology}

Craniofacial injuries can be life threatening (involvement of airway i.e. blood in oral cavity or in nose, injuries to neck vessels i.e. carotid and vertebral arteries or injuries to the brain and spine) requiring special attention or can be aesthetically significant. A number of etiologic factors (ranging from road traffic accidents to assaults), demographic properties and fracture patterns have been identified which varies widely (due to social, economic, cultural consequences) in different regions of the world. (4-8) Leading cause of facial injuries include motor vehicle accidents, pedestrian collisions, stumbling, sports injuries, industrial accidents, assaults and warfare injuries. (9-13) However all the patients may not be attended by a singly facility i.e. may go to emergency room, may go to craniofacial faculties or may be seen by a neurosurgeon depending on the complexities of their injuries. $(1,14-16)$

\section{Clinical evaluation}

Craniofacial skeleton can be divided into upper third (above superior orbital rim), middle third (midface- superior orbital rim down through maxillary teeth) and lower third - mandible. It is mainly composed of frontal bone, temporal bones, nasal bone, zygomas, maxilla and mandible. In addition ethmoid, lacrimal, sphenoid bones contribute to inner part of the orbits. (17) Facial injuries can be categorized into soft tissue injuries, skeletal injuries and a combination of both. Like any other discipline of medicine clinical evaluation start with details history taking. The details which need to be included are the mechanism of injury, any history of loss of consciousness, any history of previous medical or surgical disease. The detail history should include in what circumstances injury has occurred, ask details about the direction of the impact and speed of the vehicle.

\section{Physical Examination}

Detail physical examination include careful but gentle palpation, assessment of mobility of bone fragments, and numbness or paresthesia, occlusal malfunction, assessment of integrity of the mandible, detail ocular examination including test for visual acuity (Table 1). (1820) One need to remember that in juries to the facial skeleton are of special concern as these can be a marker for substantial transfer of energy to the intracranial contents. (21)

\section{Associated injuries}

Craniofacial injuries can be associated with many other concomitant life-threatening systemic injuries i.e. cranial trauma, limbs fractures, chest injuries, spinal injuries and orbital injuries. (22-30) Evaluation of these patients should include a coordinated and systematic examination to aim to evaluate of all areas, local or general, in order not to miss any of the injuries. All the residents while examining these patients in emergency room should remember that facial swelling, altered sensorium, restless patient, presence of endotracheal and nasogastric tube can obscure the detail examination and distort the facial appearance. 
TABLE 1

Key findings to suspect craniofacial injuries of physical examination

\begin{tabular}{|c|c|}
\hline Type of injury & Examination findings \\
\hline General considerations & 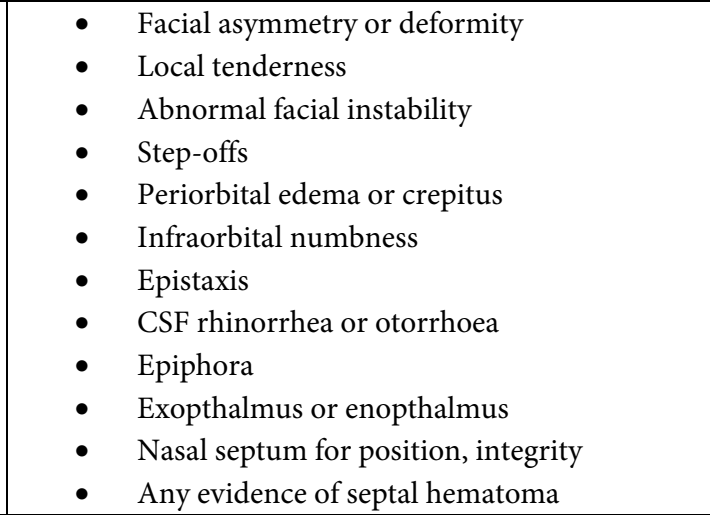 \\
\hline Epistaxis & $\begin{array}{l}\text { Mucosal disruption } \\
\text { Disruption of the membrane of maxillary sinus }\end{array}$ \\
\hline Abnormal occlusion & Mandibular fracture preventing normal movements \\
\hline Malar fracture & $\begin{array}{l}\text { Infra orbital/upper lip numbness on the affected side } \\
\text { The affected side of face may be flattened } \\
\text { Periorbital edema } \\
\text { Ecchymosis of the lower lid } \\
\text { Lateral sub-conjunctival hemorrhage }\end{array}$ \\
\hline Zygomatic arch fractures & $\begin{array}{l}\text { A dimple palpable on the arch } \\
\text { Local tenderness } \\
\text { Restricted range of mouth opening }\end{array}$ \\
\hline Ocular injuries & $\begin{array}{l}\text { Suggest midface trauma } \\
\text { Check for ocular integrity } \\
\text { Telecanthus } \\
\text { Orbital muscle/nerve entrapment } \\
\text { Check extraoccular motility } \\
\text { Test visual acuity and visual fields } \\
\text { Check pupillary light reflex }\end{array}$ \\
\hline Cranial nerves & $\begin{array}{l}\text { Details neurological examination (including motor and } \\
\text { sensory divisions) of all } 12 \text { cranial nerves }\end{array}$ \\
\hline $\begin{array}{l}\text { Traumatic brain injury (suspect intracranial } \\
\text { hemorrhages, cerebral contusion or laceration, or skull } \\
\text { fractures) }\end{array}$ & $\begin{array}{l}\text { History of vomiting } \\
\text { Loss of consciousness } \\
\text { Low Glasgow Coma Scale }\end{array}$ \\
\hline
\end{tabular}

\section{Investigations}

Apart from the basic blood investigations (e.g. Hb, PCV, ESR, WBC estimations) the specific radiological investigations depend of the clinical indications and include plain radiographs, CT scan and on MRI. 


\section{Plain radiographs}

Plain radiographs have a limited role (less sensitivity to detect fractures of the skull base and facial skeleton) in the radiological evaluation of facial injuries and include skull radiographs (lateral as well as postanterior view), panorex radiographs (to evaluate the mandible), submentvertex view (to evaluate the zygomatic arch) cervical spine examination. While reading the radiographs a systematic approach (How the orbital outline, sinuses is are clear or is there any opacification or fluid levels suggestive of a fracture) will help to identify the facial fractures.

\section{Computed tomography (CT scan)}

Recently with the development of multislice CT and with significant technical advancement computed tomography (CT) has become the primary modality of imaging. CT scan detects cranio- facial injuries in detail and can help to exclude intracranial hemorrhages and can assess, identify and classify associated bone injuries. $(31,32) \mathrm{CT}$ scan can also help to differentiated fracture in anatomically difficult areas which cannot be seen on conventional radiographs (e.g., the orbits, the naso-orbitoethmoidal complex, the peri- and retroorbital skull base and the retro- maxillary region). (24, 33) CT scan has the additional advantage that it can be extended to the cervical spine (if necessary whole spine, thorax and abdomen) in an unstable with polytrauma. CT scan also has the capacity to evaluate the facial skeleton in axial and coronal planes. (Hassfeld et al. 1998; Gellrich et al. 1999, 2003) Computer assisted multiplanar reformatting allows to detect or exclude basal skull fractures, optic canal, orbital floor, maxilla, palate, and mandible fractures as well as the extent of different dislocations. $(34,35)$

\section{Magnetic resonance imaging (MRI)}

MRI may be used to investigate diffuse axonal injuries and in evaluating complications (i.e. CSF rhinorrhea). (36) MRI and MR angiography is helpful for the investigations of skull base trauma in cases of carotid-cavernous sinus fistula. MRI has a limited role particularly in a polytrauma patient with traumatic brain injury as it is more time-consuming than $\mathrm{CT}$ and much less effective in detecting fractures than CT. Presence of cardiac pacemakers and other implanted metals and electronic devices further limiting factors to perfume an MRI.

\section{Management}

\section{Initial management}

The initial management of any patient with the clinical suspicion of craniofacial who comes to the emergency room follows standard protocol i.e. airway management, breathing and circulation. Once the general condition of the patient is stabilized further investigations and appropriate surgical intervention can be planned (Table 2). Maintenance of the airway in of primary importance (adequate suction, removal of nay foreign bodies or blood clot from the oral cavity), chin lift or jaw thrust to prevent tongue fall, pulling of the maxilla forward to disimpact the fracture, endotracheal intubation (or laryngeal mask airway) and if all these measures fail or not possible than an option to provide surgical airway needs to be considered (i.e. cricothyroidotomy or 
DOI: $10.2478 /$ romneu-2014-0047

tracheostomy). While securing the airway look for any active source of bleeding (injury to the major neck vessels, massive midface fractures, extensive scalp lacerations etc.) and take

\section{TABLE 2}

\section{Summary of initial resuscitation approach and management}

\begin{tabular}{|c|c|}
\hline Primary Survey & $\begin{array}{l}\text { - Allows rapid assessment of vital functions (pulse, blood } \\
\text { pressure and oxygen saturation) and help to identify life- } \\
\text { threatening conditions }\end{array}$ \\
\hline Airway \& breathing & 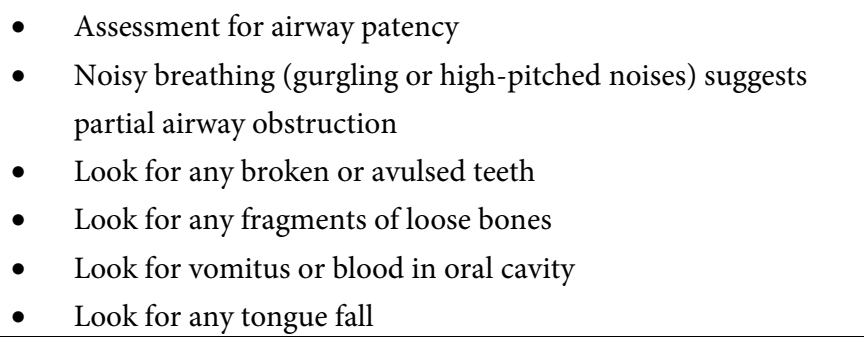 \\
\hline Circulation & $\begin{array}{l}\text { - } \quad \text { Look for any source of massive bleeding scalp lacerations } \\
\text { - } \\
\text { - } \quad \text { Levere midrace fractures may result massive blood loss } \\
\text { hemoperitoneum, long bone fractures etc.) }\end{array}$ \\
\hline Disability & $\begin{array}{l}\text { - } \\
\text { - } \\
\text { Assess of the patient's Glasgow Coma Scale (GCS) score } \\
\text { Anyological deficits }\end{array}$ \\
\hline Secondary Survey (see Table 1) & $\begin{array}{l}\text { - It should be performed once the primary survey is complete } \\
\text { and life-threatening conditions have been ruled out or } \\
\text { managed } \\
\text { A complete head-to-toe assessment so no injuries should be } \\
\text { missed }\end{array}$ \\
\hline
\end{tabular}

\section{TABLE 3}

\section{Basic principal for the management of facial injuries}

- Never shaved eyebrows

- Repair with precise attention to the normal shape and borders (lips, nose and eyebrows)

- Accurately restored the bony framework and soft tissue of the nose

- Nasal septum hematoma needs surgical draining as it can cause dissolution of the septal cartilage

- Epistaxsis can be controlled with head end elevation, cold compression and if necessary internal compression

- While managing fractures either it should be done before a significant edema is develops or once the edema is resolved (5-7 days after the injury) 


\section{Surgical intervention}

Once the patient general condition is stabilized, all the life threatening injuries are taken care off and a thorough clinical examination has been performed to rule out any intracranial injuries, surgery can be planned for facial injuries. Before planning for surgery identifies the extent of injuries i.e. whether these are soft tissue injuries (contusions, abrasions, puncture wounds, lacerations or abrasions) or involve the facial skeleton (fractures of different bones) or it is a combination of both. The purpose of surgical intervention is to regain the function with good aesthetic outcome (Table 3). Open facial wounds need thorough cleaning, meticulous approximation, conservative debridement and if necessary graft to cover the raw surfaces. Fractures will need rigid fixation of the fragments (by bone mini-plates and screws) to achieve perfect reduction, alignment and also needs good soft tissue cover and adequate time for bone healing to get completed.

\section{Conclusion}

Craniofacial injuries can occur in a significant proportion in traumatic brain injury patients and these will require prompt diagnosis and management. The management of these injuries is a challenge which is faced by residents in emergency room. An understanding of the presentations of craniofacial injuries, associated systemic injuries and patterns of traumatic brain injuries is crucial for improving care, survival and recovery of these patients.

\section{Correspondence}

Dr Amit Agrawal

Professor of Neurosurgery

Department of Neurosurgery

Narayana Medical College Hospital

Chinthareddypalem

Nellore-524003

Andhra Pradesh (India)

Email-dramitagrawal@gmail.com

dramit_in@yahoo.com

Mobile- +91-8096410032

\section{References}

1.Malara P, Malara B, Drugacz J. Characteristics of maxillofacial injuries resulting from road traffic accidents--a 5 year review of the case records from Department of Maxillofacial Surgery in Katowice, Poland. Head \& face medicine 2006;2:27.

2.Hull AM, Lowe T, Finlay PM. The psychological impact of maxillofacial trauma: an overview of reactions to trauma. Oral surgery, oral medicine, oral pathology, oral radiology, and endodontics 2003;95:515-520.

3.Klotch DW. Frontal sinus fractures: anterior skull base. Facial plastic surgery 2000;16:127-134.

4.Arslan ED, Solakoglu AG, Komut E, et al. Assessment of maxillofacial trauma in emergency department. World Journal of Emergency Surgery 2014;9:13.

5.Aksoy E, Unlü E, Sensöz O. A retrospective study on epidemiology and treatment of maxillofacial fractures. The Journal of craniofacial surgery 2002;13:772-775. 6.Erol B, Tanrikulu R, Görgün B. Maxillofacial fractures. Analysis of demographic distribution and treatment in 2901 patients (25-year experience). Journal of craniomaxillo-facial surgery 2004;32:308-313.

7.Haug RH, Foss J. Maxillofacial injuries in the pediatric patient. Oral surgery, oral medicine, oral pathology, oral radiology, and endodontics 2000;90:126-134.

8.Wood EB, Freer TJ. Incidence and aetiology of facial injuries resulting from motor vehicle accidents in Queensland for a three-year period. Australian dental journal 2001;46:284-288.

9.Gassner R, Tuli T, Hächl O, Rudisch A, Ulmer H. Cranio-maxillofacial trauma: a 10 year review of 9,543 cases with 21,067 injuries. Journal of cranio-maxillofacial surgery 2003;31:51-61.

10.Lee JH, Cho BK, Park WJ. A 4-year retrospective study of facial fractures on Jeju, Korea. Journal of craniomaxillo-facial surgery 2010;38:192-196. 
DOI: 10.2478/romneu-2014-0047

11.van den Bergh B, Karagozoglu KH, Heymans MW, Forouzanfar T. Aetiology and incidence of maxillofacial trauma in Amsterdam: a retrospective analysis of 579 patients. Journal of cranio-maxillo-facial surgery 2012;40:e165-169.

12.Gandhi S, Ranganathan LK, Solanki M, Mathew GC, Singh I, Bither S. Pattern of maxillofacial fractures at a tertiary hospital in northern India: a 4-year retrospective study of 718 patients. Dental traumatology 2011;27:257262.

13.Maliska MCdS, Lima Júnior SM, Gil JN. Analysis of 185 maxillofacial fractures in the state of Santa Catarina, Brazil. Brazilian oral research 2009;23:268-274.

14.Rosman DL, Knuiman MW. A comparison of hospital and police road injury data. Accident; analysis and prevention 1994;26:215-222.

15.Rajendra PB, Mathew TP, Agrawal A, Sabharawal G. Characteristics of associated craniofacial trauma in patients with head injuries: An experience with 100 cases. Journal of Emergencies, Trauma \& Shock 2009;2.

16.Agrawal A, Prasad R, Shetty L, Nachiappan S, Manju M. Characteristics of craniofacial trauma in a rural hospital in South India. Annals of African Medicine 2006;5:33-37.

17.Gray J. Gray's anatomy: Random House LLC, 2010.

18.Eggensperger $\mathrm{N}$, Smolka $\mathrm{K}$, Scheidegger $\mathrm{B}$, Zimmermann H, Iizuka T. A 3-year survey of assaultrelated maxillofacial fractures in central Switzerland. Journal of cranio-maxillo-facial surgery 2007;35:161-167. 19.Lee KH, Snape L, Steenberg LJ, Worthington J. Comparison between interpersonal violence and motor vehicle accidents in the aetiology of maxillofacial fractures. ANZ journal of surgery 2007;77:695-698.

20.Kloss F, Laimer K, Hohlrieder M, et al. Traumatic intracranial haemorrhage in conscious patients with facial fractures--a review of 1959 cases. Journal of craniomaxillo-facial surgery 2008;36:372-377.

21.Hohlrieder M, Hinterhoelzl J, Ulmer H, Hackl W, Schmutzhard E, Gassner R. Maxillofacial fractures masking traumatic intracranial hemorrhages. International journal of oral and maxillofacial surgery 2004;33:389-395.

22.Béogo R, Dakouré P, Savadogo LB, Coulibaly AT, Ouoba K. Associated injuries in patients with facial fractures: a review of 604 patients. Pan African Medical Journal 2013;16.

23.Thorén H, Snäll J, Salo J, et al. Occurrence and types of associated injuries in patients with fractures of the facial bones. Journal of oral and maxillofacial surgery 2010;68:805-810.

24.Scherbaum Eidt JM, De Conto F, De Bortoli MM,
Engelmann JL, Rocha FD. Associated injuries in patients with maxillofacial trauma at the hospital são vicente de paulo, passo fundo, Brazil. Journal of oral \& maxillofacial research 2013;4:e1.

25.Udeabor S, Akinmoladun VI, Olusanya A, Obiechina A. Pattern of midface trauma with associated concomitant injuries in a nigerian referral centre. Nigerian journal of surgery 2014;20:26-29.

26.Alvi A, Doherty T, Lewen G. Facial fractures and concomitant injuries in trauma patients. The Laryngoscope 2003;113:102-106.

27.Follmar KE, Debruijn M, Baccarani A, et al. Concomitant injuries in patients with panfacial fractures. The Journal of trauma 2007;63:831-835.

28.Lim LH, Lam LK, Moore MH, Trott JA, David DJ. Associated injuries in facial fractures: review of 839 patients. British journal of plastic surgery 1993;46:635638.

29.Gwyn PP, Carraway JH, Horton CE, Adamson JE, Mladick RA. Facial fractures--associated injuries and complications. Plastic and reconstructive surgery 1971;47:225-230.

30.Tung TC, Tseng WS, Chen CT, Lai JP, Chen YR. Acute life-threatening injuries in facial fracture patients: a review of 1,025 patients. The Journal of trauma 2000;49:420-424.

31.Bull H, Choy M, Manyonda I, et al. Reactivity and assay restriction profiles of monoclonal and polyclonal antibodies to acid phosphatases: a preliminary study. Immunology letters 1999;70:143-149.

32.Lehmann ED. Simulating glycosylated hemoglobin (HbAlc) levels in diabetes using an interactive educational virtual diabetes patient simulator. Diabetes technology \& therapeutics 2001;3:517-524.

33. Whitaker K, Al K, Abbasi K, Dias P. Compound anterior cranial base fractures classification using computerized to mograph scanning as a basis for selection of patients for dural repair. J Neurosurg 1998;88:471-478.

34.Joss U, Piffko J, Meyer U. Behandlung von frontobasalen Traumen und Polytraumen. Mund Kiefer Gesichtschir 2001;5:86-93.

35.Probst W, Fischer JA, Binswanger U. Intravenous $1,25(\mathrm{OH}) 2$ vitamin $\mathrm{D} 3$ therapy in haemodialysis patients: evaluation of direct and calcium-mediated short-term effects on serum parathyroid hormone concentration. Nephrology, dialysis, transplantation 1990;5:457-460. 36.Yokota H, Kurokawa A, Otsuka T, Kobayashi S, Nakazawa S. Significance of magnetic resonance imaging in acute head injury. The Journal of trauma 1991;31:351357. 